\title{
Optimisation of sampling for the temporal monitoring of technetium-99 in the Arctic marine environment
}

\author{
Mark Dowdall ${ }^{\mathrm{a}, *}$, Sebastian Gerland ${ }^{\mathrm{b}}$, \\ Michael Karcher ${ }^{c, d}$, Justin P. Gwynn ${ }^{\text {a', }}$ \\ Anne Liv Rudjord ${ }^{\mathrm{e}}$, Anne Katherine Kolstad ${ }^{\mathrm{e}}$ \\ ${ }^{a}$ Environmental Unit, Norwegian Radiation Protection Authority, \\ Polar Environmental Centre, 9296 Tromso, Norway \\ ${ }^{\mathrm{b}}$ Norwegian Polar Institute, Polar Environmental Centre, 9296 Tromsø, Norway \\ ${ }^{\mathrm{c}}$ Alfred Wegner Institute for Polar and Marine Research, Postfach 12 0161, \\ $D$-27515 Bremerhaven, Germany \\ ${ }^{\mathrm{d}}$ O.A.Sys - Ocean Atmopshere Systems, Schanzenstr. 36, D-20357 Hamburg, Germany \\ ${ }^{\mathrm{e}}$ Norwegian Radiation Protection Authority, PO Box 55, N-1332 Østerås, Norway
}

Received 26 November 2004; received in revised form 6 April 2005; accepted 7 April 2005 Available online 9 June 2005

\begin{abstract}
Monitoring of the marine environment for radioactivity, for both radiological protection and oceanographic purposes, remains an expensive and labour intensive activity due to the large sample volumes needed and the complex and lengthy analytical procedures required to measure low levels of contamination. Because of this, some consideration must be given to the design of sampling plans to ensure effective and efficient sampling that can be defended on the basis of scientific rationale. This article tests the hypothesis that geostatistical techniques may prove of use in the optimisation and design of sampling regimes for the monitoring of temporal fluctuations in the levels of technetium at a location in the Norwegian Arctic marine environment. The level of temporal correlation exhibited by two relevant time series was
\end{abstract}

\footnotetext{
* Corresponding author. Fax: +47 77750171 .

E-mail address: mark.dowdall@nrpa.no (M. Dowdall).
} 
investigated and the information used to observe the effect of sampling frequency on the production of monthly estimates of activity of technetium in both seawater and seaweed. The results indicate that reduced sampling frequency allows production of estimates that acceptably replicate the actual data and that use of geostatistical procedures may offer advantages in the planning of monitoring systems for marine radioactivity. The use of an oceanographic model was also investigated as a means of assessing the temporal correlation prior to actual sampling, an approach that may offer significant advantages by reducing the need to have lengthy time series prior to designing sampling regimes.

(C) 2005 Elsevier Ltd. All rights reserved.

Keywords: Radioactivity; Monitoring; Technetium-99; Arctic; Sampling

\section{Introduction}

\subsection{Occurrence and monitoring of technetium-99 $\left({ }^{99} T \mathrm{Tc}\right)$ in the marine environment}

Monitoring of radioactivity in the Arctic marine environment is of special significance due to the particular vulnerability of the environment and its constituent ecosystems. In recent years much attention has been devoted to the presence of the radioactive contaminant ${ }^{99} \mathrm{Tc}$ in the Norwegian marine environment, the main source of this contamination being activities conducted at European nuclear reprocessing facilities (Fig. 1). The discovery of elevated ${ }^{99} \mathrm{Tc}$ levels in the Norwegian Arctic marine environment (Brown et al., 1998) precipitated the initiation of monitoring activities by the Norwegian Radiation Protection Authority, within the framework of the national programme for monitoring of Radioactivity in the Marine Environment (RAME), to assess and elucidate the levels and behaviour of this contaminant in the Norwegian Arctic marine environment. Technetium-99 also constitutes as an important oceanographic tracer (Aarkrog et al., 1987) and monitoring of the isotope provides information of pertinence towards the further understanding of oceanographic processes and contaminant pathways.

Technetium-99 is a fission product of uranium and is formed during nuclear reactions by the beta decay of molybdenum- 99 . Technetium-99, with a half-life of 213000 years and a specific activity of $630 \mathrm{kBq} / \mathrm{mg}$, undergoes beta decay to form the stable isotope ${ }^{99} \mathrm{Ru}$. The greatest source of ${ }^{99} \mathrm{Tc}$ in the environment is the operation of nuclear reactors and associated facilities in the nuclear industry. An estimated 25-30 ton of the isotopes have been produced worldwide with approximately $1 \%$ of that amount $(150-200 \mathrm{TBq})$ having been released to the environment (Aarkrog et al., 1986; Beasley and Lorz, 1986).

The long half-life of ${ }^{99} \mathrm{Tc}$, its high environmental mobility as the poorly sorbed, chemically stable, anionic pertechnate species $\left(\mathrm{TcO}_{4}^{-}\right)$and its infiltration of food chains as an analogue of sulphate (Bondietti and Francis, 1979; Cataldo et al., 1989) 
(a)

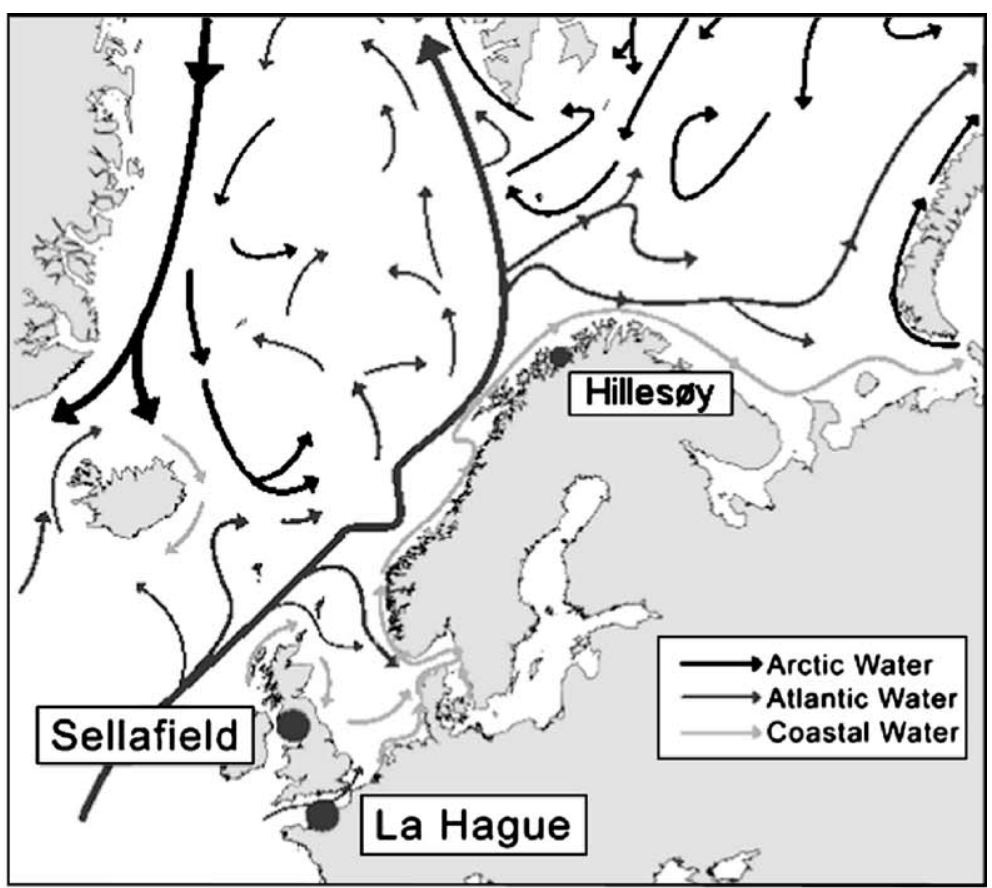

(b)

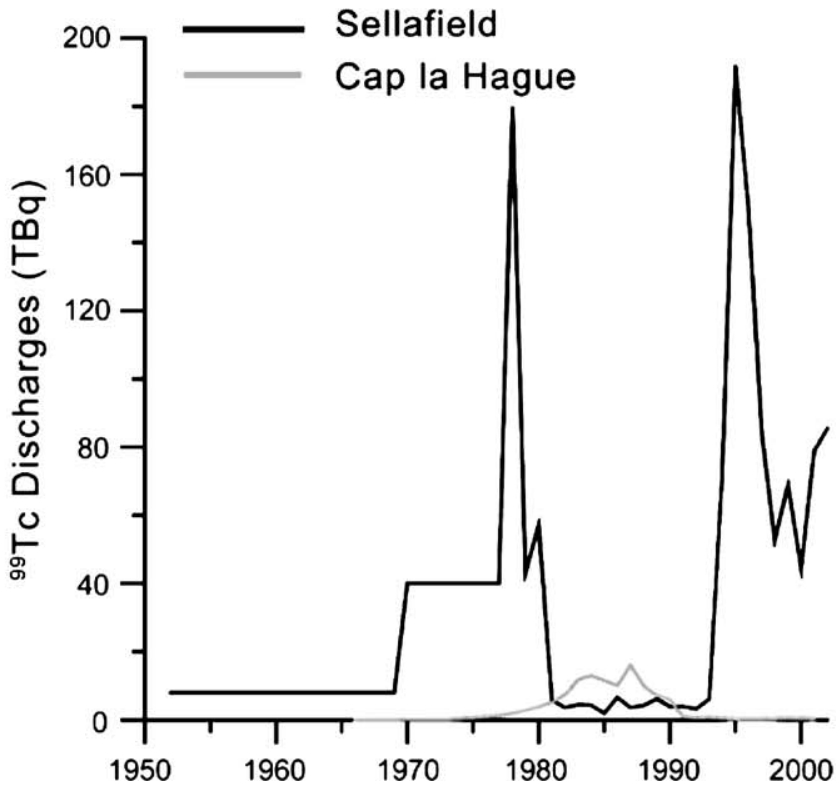

Fig. 1. (a) Depiction of sources of ${ }^{99} \mathrm{Tc}$ to the northern marine environment, relevant ocean currents and the location of the study site in northern Norway. (b) Variation in magnitude of ${ }^{99} \mathrm{Tc}$ discharges from Sellafield and Cap le Hague with time. 
make the contamination of the environment with this isotope a matter of some concern. Past and continued sources of ${ }^{99} \mathrm{Tc}$ in the Norwegian marine environment are the nuclear fuel reprocessing facilities at Sellafield in the UK and Cap la Hague in France (Fig. 1a.), both plants being engaged in the reprocessing of spent fuel from nuclear reactors. Discharges of ${ }^{99} \mathrm{Tc}$ from these facilities have varied in magnitude over the past decades, an overview being provided in Fig. 1b. Details of ${ }^{99} \mathrm{Tc}$ discharges from both plants may be found in BNFL (1982-1991), Herrmann et al. (1995), Leonard et al. (1997) and Busby et al. (1997).

The findings of Brown et al. (1998) indicated that ${ }^{99} \mathrm{Tc}$ from the increased Sellafield discharges beginning in 1994 (Fig. 1b) had reached Norwegian coastal waters some time before November 1996 and could be detected off Northern Norway by December 1997. ${ }^{99} \mathrm{Tc}$ is transported to Norwegian waters by the Norwegian Coastal Current via the North Sea. This current continues along the Norwegian coast before flowing further north with the West Spitsbergen Current towards Svalbard and into the Barents Sea as the North Cape Current, transporting any contaminant load into the Norwegian Arctic marine environment. The most recent data (for 2002) regarding levels of ${ }^{99} \mathrm{Tc}$ in the waters and biota off mainland Northern Norway indicate an average level of $1.3 \pm 0.3 \mathrm{~Bq} / \mathrm{m}^{3}$ in seawater and $320 \pm 70 \mathrm{~Bq} / \mathrm{m}^{3}$ in seaweed (Gäfvert et al., 2004).

In 1999, sampling and analysis of waters and biota along the Norwegian coast by the Norwegian Radiation Protection Authority increased under the new marine monitoring programme (RAME) funded by the Ministry of the Environment. The primary objectives of RAME are to monitor and document levels of and trends in radionuclide contamination in Norwegian waters. Monitoring activities involve the taking of large volume water samples $(50-1001)$ for subsequent radiochemical analysis of ${ }^{99} \mathrm{Tc}$. The logistical problems involved in the taking of such samples and the nature of the radiochemical analysis necessitates the optimisation of sampling regimes with respect to frequency and the quality of the information required regarding levels of the isotope in the samples taken. With a view towards establishing a defensible rationale for the design of the monitoring plan, geostatistical methods were investigated as forming the basis for the improved monitoring design.

\subsection{Optimisation of sampling: geostatistical methods}

Geostatistical methods and procedures have become widespread in the field of spatial interpolation and estimation. The methods are based around the fundamental works by Krige (1951) and Matheron (1963) and essentially relate to the concept of Regionalised Variables (ReV's). The two characteristics defining a Regionalised Variable are:

1. An observation of the variable at point or time $w_{i}$ within the greater area or time $w$ is a realisation of a random variable $Z\left(w_{i}\right)$ for the point $w_{i}$. This component is random in that the set of random variables for every point confined by $w$ is a random function. 
2. The random variables for two locations, $w_{i}$ and $w_{i+h}$ (separated by vector or time $h)$ are not considered independent, i.e. $Z\left(w_{i}\right)$ and $Z\left(w_{i+h}\right)$ are spatially or temporally correlated.

A thorough treatment of the constraints related to Regionalised Variables and their characteristics can be found in Matheron (1963). Semi-variography is the first stage in a geostatistical analysis, the semi-variogram being a graphical representation of how the similarity between variable values varies as a function of the distance (and direction) or time separating them. The theoretical semi-variogram is a plot of onehalf of the variance of the differences in variable values ( $y$-axis) as a function of the distance, or "lag", separating pairs of points ( $x$-axis), the general equation for the semi-variogram being:

$$
\gamma(h)=\frac{1}{2 n(h)} \sum_{i=1}^{n-h}\left[z\left(x_{i+h}\right)-z\left(x_{i}\right)\right]^{2}
$$

where $\gamma(h)$ is the semi-variance, $n(h)$ is the number of points separated by the time or distance $h$ (the "lag") and $\left[z\left(x_{i}+h\right)-z\left(x_{i}\right)\right]$ is the difference between the values of variables separated by the lag $h$.

As only a limited number of pairs are available in a practical study, an experimental semi-variogram is plotted using the available data and a theoretical model is fitted to the resulting plot. The curve fitted to the data can be seen to usually consist of two distinct parts, an initial rising segment and a second, level region. The point at which the curve levels off is used to calculate both the sill ( $y$-axis) and the range of correlation ( $x$-axis). The sill is the maximum semi-variance exhibited by the data set and the range of correlation is the lag (or separation distance or time) at which the sill value is reached. Pairs of points separated by a distance or time greater than the range of correlation are considered to be spatially or temporally uncorrelated. A sample can be taken as representative of an area or time defined by the range of correlation. The range of correlation provides a mathematical means of measuring the "area of influence" as described in other estimation methods. The semi-variance value indicated by the sill can be divided into two components, the "nugget effect", often-denoted Co, represents the random variance in the data and is calculated as the value at which the semi-variogram crosses the $y$-axis. The structured semi-variance is the component of the data set's variance represented by the sill value less the nugget value. The experimental semi-variogram only provides information on the data set used to construct the plot. In order to describe the entire period (and lag distances for which a semi-variogram value has not been computed), it is necessary to fit a mathematical model to the data to produce the theoretical semi-variogram. A number of models are frequently used to describe the theoretical semi-variogram including Gaussian, linear and exponential models. A rigorous description of the theory and practice of semi-variography may be found in any of the following: Clarke (1979), Flatman and Yfantis (1984), Srivastava and Isaaks (1989). 
The second stage of a geostatistical analysis involves the estimation of variable values at unsampled locations or times using the estimation method known as kriging (Krige, 1951). The estimation method employs a weighted moving average interpolation procedure, weights being assigned to known samples on the basis of the information in the semi-variogram. Generally, the closest neighbouring samples are attributed the greatest weights although in a data set exhibiting geometric anisotropy, a sample a distance away from an unknown point may be attributed a heavier weighting than a nearer sample depending on the ranges of influence in the two directions. Kriging may either produce estimates for points in space or time (punctual) or for three dimensional volumes (block kriging). Block kriging is usually implemented in the estimation of ore bodies or similar phenomena, punctual kriging being used more often in environmental studies. The function for point kriging is:

$$
z^{*}\left(t_{0}\right)=\sum_{i=1}^{n} \lambda_{j} z\left(t_{j}\right)
$$

where $z^{*}\left(t_{0}\right)$ is the estimate value at the unknown location or time $t_{0}, \lambda_{j}$ being the weight assigned to the known sample $z$ at $\left(t_{j}\right)$. The weights are assigned according to the following equation, subject to a number of constraints:

$$
\sum_{j=1}^{n} \lambda_{i} \gamma\left(t_{i}, t_{j}\right)+\mu=\gamma\left(t_{j}, t_{0}\right) \quad i=1,2, \ldots, n
$$

$\left(t_{i}, t_{j}\right)$ being the time separating points $t_{i}$ and $t_{j},\left(t_{i}, t_{0}\right)$ being the time between the unknown point $t_{0}$ and the known point $t_{i}, \mu$ is a Lagrange multiplier. A distortion free distribution of weights is obtained by using the following constraint:

$$
\sum_{i=1}^{n} \lambda_{i}=1
$$

A much vaunted advantage to kriging as an estimation method is the production of a measure of uncertainty associated with the produced estimates. The production of this indicator of the estimate reliability (known as the "kriging standard deviation") is achieved as demonstrated in the following example. A time $t$, for which we wish to estimate the value of the variable $q$, is surrounded by many other points for which the value of $q$ is known. A semi-variogram for the data set which contains these points has been calculated and a theoretical model has been fitted. When the value of $q$ at $t$ is estimated an error is incurred:

$$
\text { error }=q_{t}-q_{t}^{*}
$$

where $q_{t}$ is the actual value of the variable $q$ at $t$ and $q_{t}^{*}$ is the estimate of the value of the variable $q$ at $t$. If the estimating procedure is unbiased (i.e. no trend present and a normal distribution of errors) then repeated estimations of $q_{t}^{*}$ will have an average error of 0 . The spread, or standard deviation, of these errors gives an indication of 
the reliability of the estimating procedure for the time $t$. The variance of the errors can be calculated (theoretically) as the mean squared deviation from the mean error. This is equal to:

$$
\frac{(\text { error }- \text { mean error })^{2}}{n}
$$

$n$ being the number of estimations performed. However, as the estimating procedure is unbiased, the mean error will be equal to 0 , the variance of the errors reducing to:

$$
\frac{\left(q_{t}-q_{t}^{*}\right)^{2}}{n}
$$

As the value $n$ represents the number of samples (whose values of $q$ are known) used to estimate $q_{t}^{*}$, the semi-variogram value will be known for each of the samples that constitute the set $n$, as the time that separates $t$ from each of the samples is already known (the lag value $h$ ). As the semi-variogram value is half the variance of the differences in the variable $q$ exhibited by pairs of samples separated by a time $h$, multiplication of the semi-variogram value by 2 will give a measure of the reliability associated with an estimate made based on a known sample at time $h$ away from the unknown point. Although the above example presents the situation pertaining to kriging standard deviations in a simplified manner, a consideration of the issue will indicate that the standard deviations depend on two factors only: the spacing of the known data points and the semi-variogram value. It is this feature of the process that makes it amenable to the design of sampling schemes.

The objective of this study was to attempt to utilise geostatistical procedures in the optimisation of a temporal sampling plan for ${ }^{99} \mathrm{Tc}$ levels in the marine environment. The desired output was a sampling plan that would produce monthly values for levels of the isotope in two matrices; seawater and seaweed samples. The parameter used to optimise the plan was the reliability of the produced monthly estimates as characterised by the kriging standard deviation. The methods used to conduct the study are outlined and the results are presented and discussed in relation to the stated objectives.

\section{Sampling and methods}

\subsection{The data sets}

The data sets used in this study consisted of two time series consisting of ${ }^{99} \mathrm{Tc}$ values for seawater samples and seaweed samples. The time series were drawn from Hillesøy (69.63N, 17.95E), located near Tromsø in northern Norway (Fig. 1). Samples from this location have been taken by the Norwegian Radiation Protection Authority as part of the Norwegian marine monitoring programme since July 1997 and the seawater time series used in this study begins on the 23rd of July 1997 and ends on the 30th of May 2003. As part of the programme, seaweed samples 
(Fucus vesiculosis) are also drawn from the same location and the time series utilised stretches from 23rd of July 1997 to 27th of February 2003. In both cases the sampling period is approximately 30 days although this varies. Summary statistics for all series are provided in Table $1 .{ }^{99} \mathrm{Tc}$ was measured in 501 water samples and $10 \mathrm{~g}$ seaweed samples using a radiochemical procedure described by Chen et al. (2001). Uncertainties for seawater measurements are of the order of $20 \%$ or greater, the uncertainty for seaweed being lower due to the greater analytical signal presented to the detector. Both of the data sets pass the Kolmogorov-Smirnov $(\mathrm{K}-\mathrm{S})$ test for normality (Hillesøy water: $p=0.8149$, Hillesøy seaweed: $p=0.4577$ ), evidence of trend being visible in the Hillesøy seawater series, the evidence been less apparent for the seaweed series.

\subsection{Analysis}

Semi-variograms were constructed using Variowin 2.2 (Pannatier, 1996). Maximum lag distances in all cases were limited to half the maximum temporal separation of the data points to ensure enough points for calculation with a lag tolerance of up to 10 days. In order to ascertain the validity of the applied models with respect to the correlation range and to optimise some of the conditions for the subsequently applied estimation procedure, a cross validation exercise was conducted within GEO-EAS (Englund and Sparks, 1988). This involved eliminating one point from the data set, estimating its value from the remaining data using the temporal structure determined in the semi-variographic analysis and the estimation procedure, then reinserting the point and eliminating the next. The procedure was repeated until all known points had been estimated. Comparison of the estimated values with the corresponding actual values and statistics related to the errors in the estimates allowed optimisation of the estimation process.

It was desired to obtain estimated monthly values for ${ }^{99} \mathrm{Tc}$ in seaweed and water at Hillesøy and to achieve this the temporal structure of the data sets, as characterised by the semi-variograms, was used in the kriging procedure. This was

Table 1

Summary statistics for the two time series

\begin{tabular}{lcc}
\hline & ${ }^{99} \mathrm{Tc}$ in seawater $\left(\mathrm{Bq} / \mathrm{m}^{3}\right)$ & ${ }^{99} \mathrm{Tc}$ in seaweed $(\mathrm{Bq} / \mathrm{kg})$ \\
\hline$n$ & 65 & 57 \\
Mean & 1.09 & 245.9 \\
Standard deviation & 0.37 & 92.1 \\
Minimum & 0.37 & 0.37 \\
25th Percentile & 0.85 & 197 \\
Median & 1.05 & 257.5 \\
75th Percentile & 1.285 & 309.25 \\
Maximum & 2 & 423 \\
Skewness & 0.412 & -0.156 \\
Kurtosis & -0.277 & -0.733 \\
\hline
\end{tabular}


implemented using GEO-EAS. In order to observe the effect of reducing sample number, various data points were eliminated to produce data sets based on fewer points. The average kriging standard deviation was then recorded for each run of the kriging process as a measure of the reliability of the estimates produced.

\section{Results and discussion}

The semi-variograms for the time series display strong temporal correlation (Figs. 2 and 3). For both cases Gaussian models were used to describe the temporal correlation, data for the models being contained in the captions to the relevant figures. The semi-variograms indicate that ${ }^{99} \mathrm{Tc}$ levels are relatively homogenous from month to month and for separatory periods up to approximately 1 year but tend to vary substantially with separatory periods on the yearly scale. Both series exhibit evidence of trend in the data, manifesting itself as the rising portion of the experimental semi-variogram after lag periods of about 1 year. This trend is easily explained as within any 1 year ${ }^{99} \mathrm{Tc}$ values display little variation but from year to year levels have increased over the time series period. As the trend does not manifest itself in either of the series before the sill value is reached, it is of little consequence for local estimation of values (i.e. estimation of values separated by less than the range of correlation from the weighted points). Due to this fact no attempt was made to detrend the data using an appropriate function.

As can be seen from Figs. 4 and 5, the results of the cross-validation analysis are variable. The best results were observed for the seaweed data set. Strong correlation

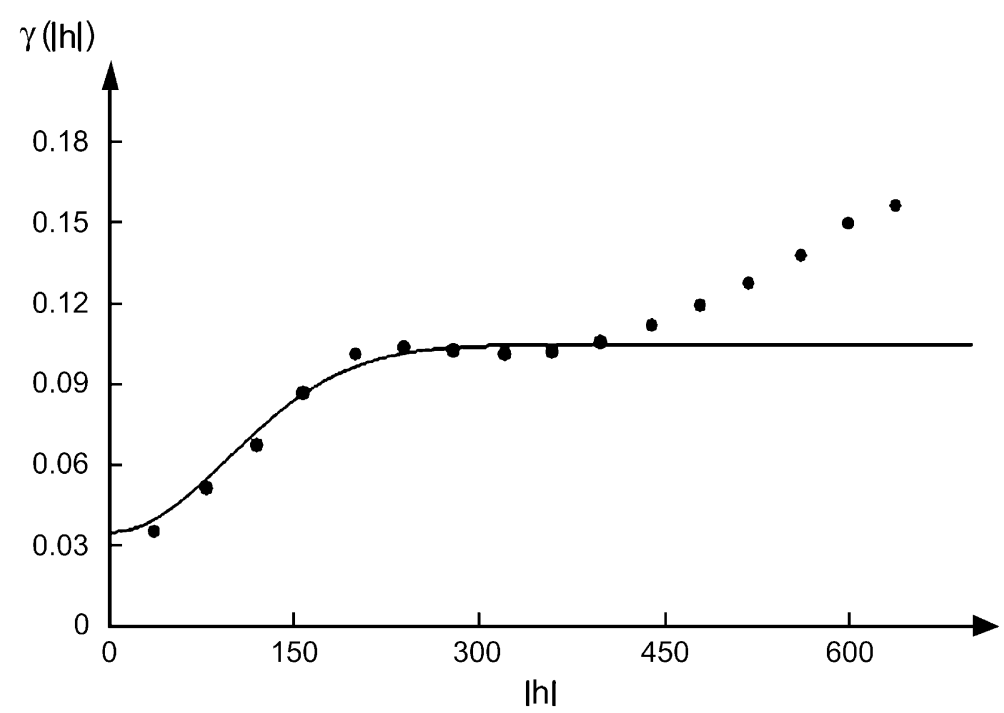

Fig. 2. Semi-variogram for ${ }^{99} \mathrm{Tc}$ values in seawater (Hillesøy). Lag $(x)$ axis - days, $\gamma(h)$ axis $-\left(\mathrm{Bq} / \mathrm{m}^{3}\right)^{2}$. Model parameters - Gaussian, range -235 days, sill -0.081 , nugget -0.034 . 


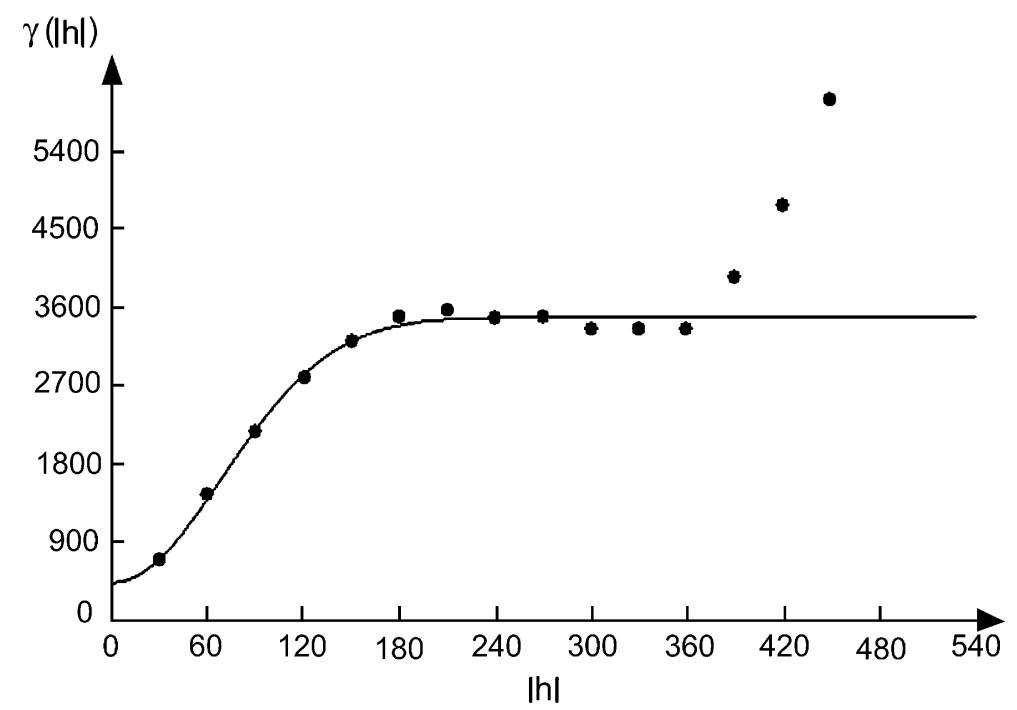

Fig. 3. Semi-variogram for ${ }^{99} \mathrm{Tc}$ values in seaweed (Hillesøy). Lag $(x)$ axis - days, $\gamma(h)$ axis $-(\mathrm{Bq} / \mathrm{kg})^{2}$. Model parameters - Gaussian, range -167 days, sill -3075 , nugget -420 .

was observed between the actual and estimated values and the time series itself was accurately reproduced, the distribution of the estimates indicating no global under or over estimation. The accuracy of the estimates for the seaweed data can be explained to some extent by the examination of semi-variogram for this time-series. The nugget value, representative of the inherent randomness of the data, is relatively small

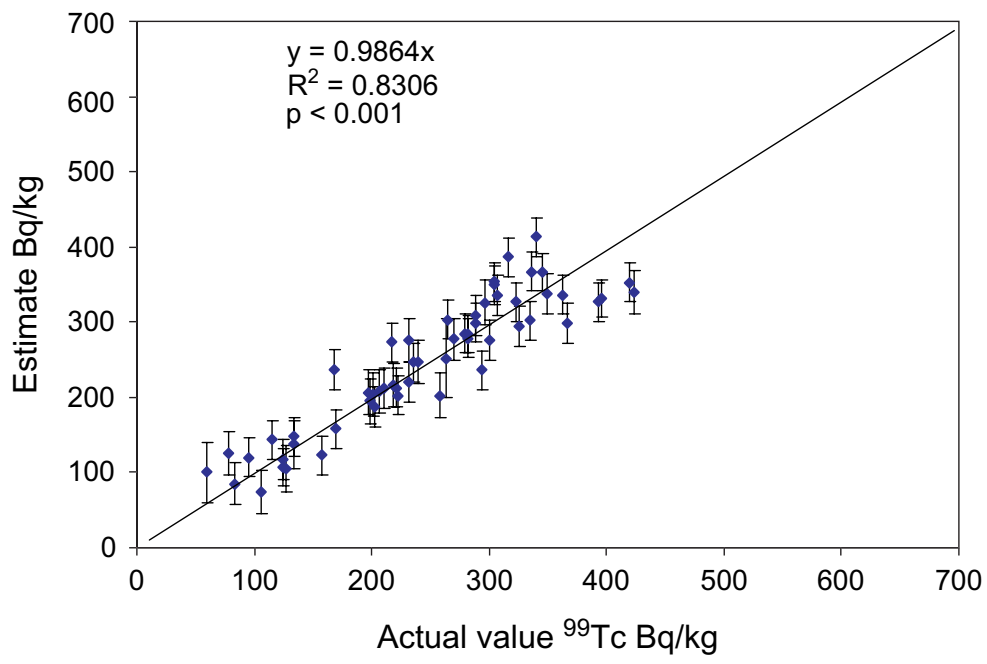

Fig. 4. Cross-validation results for the seaweed series from Hillesøy. 


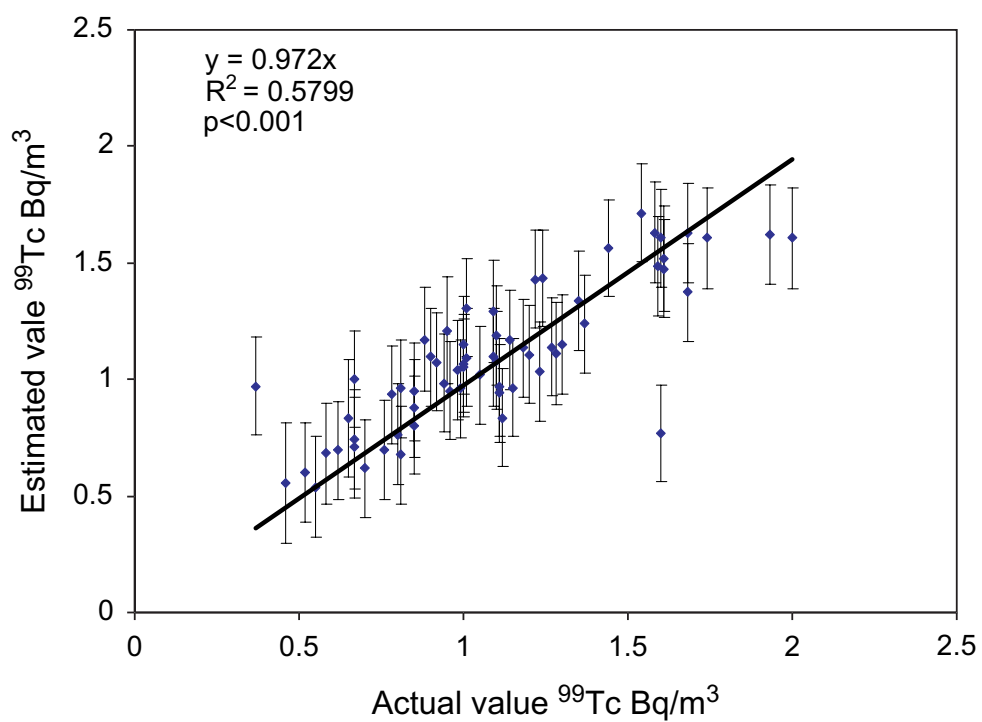

Fig. 5. Cross-validation results for the seawater time series from Hillesøy.

compared to the sill value which approaches the total semi-variance of the data. That this nugget value is small is most probably due to the fact that the analytical signal for seaweed is relatively high which reduces the associated uncertainty in the values (which contribute to the nugget parameter) and the data set itself is inherently smooth relative to the water series. The lack of extreme values relative to the general data set means that the smoothing effect of the kriging process is less and the data are better reproduced at the extreme ends of the distribution, increasing the correlation between the actual and estimated values and resulting in a more even distribution of the estimation errors across the data. Results of the analysis for the Hillesøy seawater series are less impressive (Fig. 5), some evidence of over and underestimation being present although this would appear to be primarily limited to the two extreme ends of the data distribution. The majority of these points are for low and high values in close proximity to each other but the distribution of the errors remains even. It is reasonable to expect that the seawater series would be more vulnerable to erratic estimation given the effect of local events such as freshwater runoff in spring and summer and the fact that the seaweed data are smoothed somewhat by the nature of uptake of contaminants by biota species. The distribution of the time series remains quite good. The uncertainties associated with the estimates are also proportionally higher than those associated with the seaweed data due to the greater contribution of the nugget component to the overall semi-variance of the data. The cross-validation analysis served to demonstrate that no significant bias exists in the estimation parameters employed and that realistic estimates can be obtained using those parameters. 
The implication of reduced seawater sampling frequency at Hillesøy on the average kriging standard deviation of monthly ${ }^{99}$ Tc estimates are displayed in Figs. 6 and 7. As can be seen, the uncertainty associated with the estimates is at its minimum for sample numbers approaching the actual number taken and begins to increase with reduced sample frequency. The graph indicates however that the increase in estimate uncertainty does not begin to rise dramatically until less than 30 samples were taken over the 2100 days (approximate sampling every two months), indicating that using the estimation procedure as described, monthly estimates of ${ }^{99} \mathrm{Tc}$ activity in seawater could be produced with half the number of samples taken, where the average uncertainty in the estimate would be comparable to the uncertainty in the data set resulting from 60 samples over the period. As can be seen from Fig. 8, reduced sampling accompanied by an appropriate estimation of monthly values provides essentially the same information as provided by the more intensive "real" situation. With 15 samples taken over the period (sampling approximately every 4 months) some detail is lost, mostly where estimates could not be produced due to no known points lying within the kriging search radius (in which samples for local estimation must occur). The series produced by sampling every 6 weeks is much better, no increases in activity being missed by the produced series relative to the actual data. In many cases it can be seen that the uncertainty in the estimate is slightly larger than the uncertainty reported for the actual data but this difference is not extreme in any case. The smoothing effect of the kriging procedure is clearly evident in the data although even quite small features of the actual data are reproduced in the estimated data set. Alternatively, the maximum kriging standard deviation could be used in a situation where information was required that could not

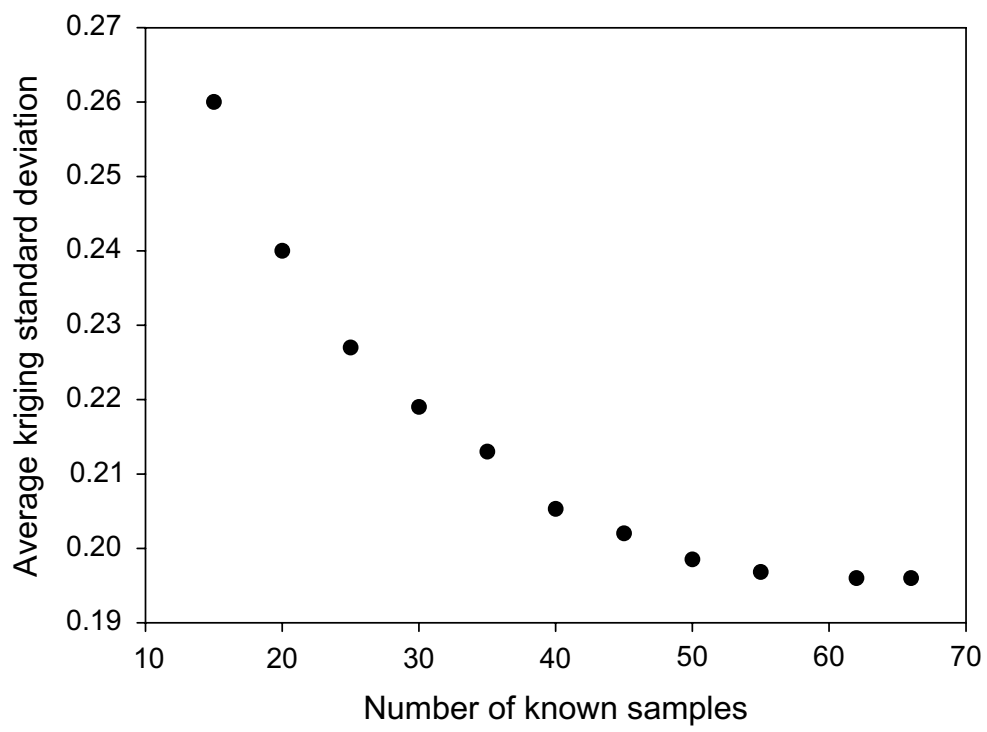

Fig. 6. Variation in average kriging standard deviation as a function of sampling frequency for seawater from Hillesøy. 


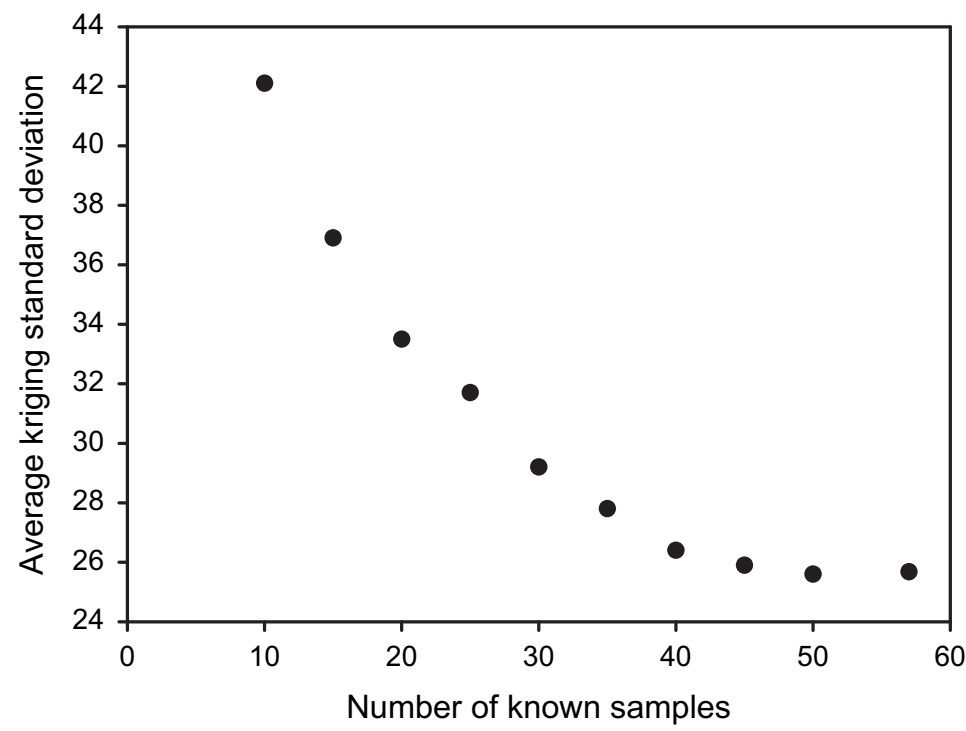

Fig. 7. Variation in average kriging standard deviation as a function of sampling frequency for seaweed from Hillesøy.

have an uncertainty of greater than a certain value. Fig. 9 displays variations in the maximum kriging uncertainty as a function of sampling frequency. The ascent is much sharper in this curve although the results indicate that little is to be gained for sample numbers greater than 40 (sampling every 50 days). The results for the seaweed data set indicate that for the 1960 day period utilised, there is little to be gained with respect to estimate quality for sample numbers greater than approximately 50 (sampling every 40 days). Fig. 10 reproduces the actual data series for a total of 20 samples and 40 samples over the period. As for the seawater data, it can be seen that the essential features of the actual series are reproduced using 40 samples but significant degradation is observed for the series that only uses 20 samples.

The above discussion has demonstrated that, for the given example of producing monthly values for ${ }^{99} \mathrm{Tc}$ (or, theoretically, any radionuclide), it is possible to produce a series of monthly data points (with associated uncertainty) using a set of samples taken on less than a monthly basis provided that:

- A level of temporal correlation exists for the data,

- The semi-variogram has been calculated and modelled and that the data conform to certain constraints (regarding 2nd order stationarity or the time-invariance of the data's probability distribution),

- The kriging estimation procedure has been optimised.

Determination of how many samples should be taken can then be based on the desired level of uncertainty in the estimated data points and the frequency for which 


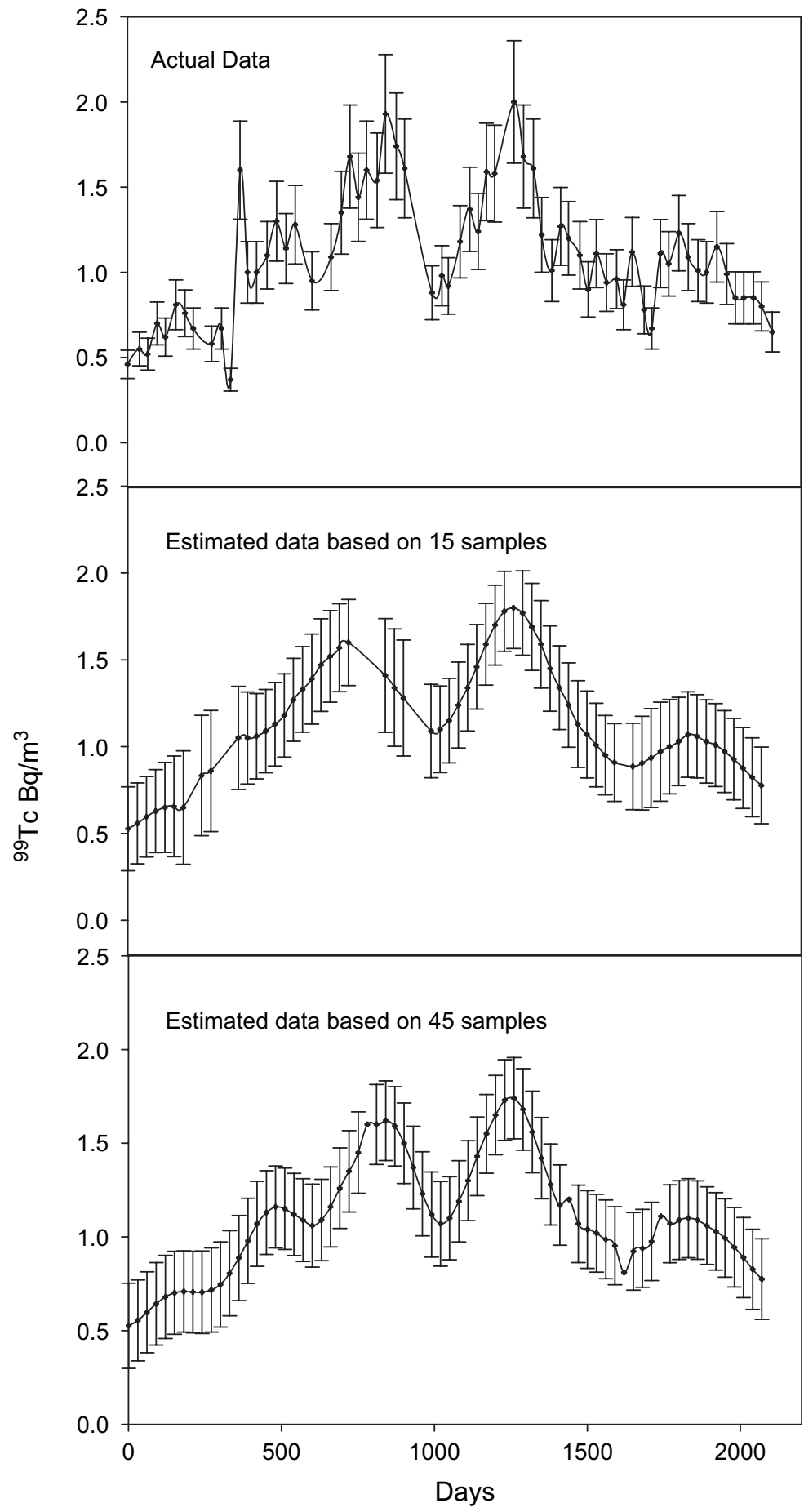


estimated points are to be produced. The problem remains however that knowledge of the semi-variogram structure must be obtained in some way prior to the optimisation of the sampling. In the design of monitoring schemes for, for example, determination of contaminant levels in soil, this is not such a problem as a one of exploratory sampling campaign can be performed prior to the design of the monitoring scheme. With temporal monitoring this is more difficult as acquiring a data set for semivariography may necessitate years of sampling. It is possible that literature data may be used or that time series from other sites may be used although both of these approaches require a high level of presumption regarding the extrapolation of data from one site to another. Although such an approach is relatively common in the spatial analysis of terrestrial parameters using geostatistical methods, it would appear that the situation for the marine environment is more complex given the nature of oceanographic processes and the local factors that may influence the observed levels of the isotope (snow melt, fresh water inputs etc.). An alternative concept may be, for the case being considered in this work, to observe if and how the contaminant signal (temporal variations in ${ }^{99} \mathrm{Tc}$ releases from Sellafield) manifests itself in the contaminant levels at the observation point. This approach however would also require a lengthy initial sampling period prior to analysing the data.

Assuming that the temporal correlation exhibited by a data set is to some extent a function of the processes involved in the occurrence of the contaminant at the location being studied, it may be possible to calculate the semi-variogram from modelled data without relying on the prior existence of a large data set. To test this approach, use was made of modelled ${ }^{99} \mathrm{Tc}$ data. The North Atlantic-Arctic Ocean Sea Ice Model (NAOSIM) (Gerdes et al., 2001; Karcher et al., 2003, 2004), developed at the Alfred Wegener Institute for Polar and Marine Research, is a 3D hydrodynamic coupled ice-ocean model, which covers the Arctic Ocean, the Nordic Seas and the North Atlantic north of $50^{\circ} \mathrm{N}$. The model is driven by daily atmospheric data from the NCEP/NCAR reanalysis dataset covering the period from 1948 to 2002. The NAOSIM model run used for the present study features a $10 \mathrm{~m}$ vertical division of the upper ocean (33 levels in total). Hydrographic initial conditions for the latest model runs are based on the most recent version of the Polar Science Centre Hydrographic Climatology (PHC), while run-off from major rivers into the model domain, including diffuse run-off and run-off from the Norwegian coast, are included. The model resolution is approximately $28 \mathrm{~km}$. After 1970, the model is subjected to an input of ${ }^{99} \mathrm{Tc}$ near the location of the nuclear reprocessing facilities in Sellafield and La Hague. While the ${ }^{99} \mathrm{Tc}$ release data are provided as yearly means from 1970 to 1994, monthly mean data are provided for the period thereafter. Simulated concentrations at Hillesøy between the beginning of 1971 and the end of 2002 are depicted in Fig. 11. As this model incorporates the hydrodynamic processes that govern the occurrence of ${ }^{99} \mathrm{Tc}$ in seawater at Hillesøy, it was decided to ascertain to what extent the model data replicated the temporal structure as

Fig. 8. Representations of ${ }^{99}$ Tc activity over time for seawater from Hillesøy based on the estimation procedure using 15 and 45 of the original data points compared with the actual data set. Error bars are the analytical uncertainty for the actual data and the kriging standard deviations for the estimates. 


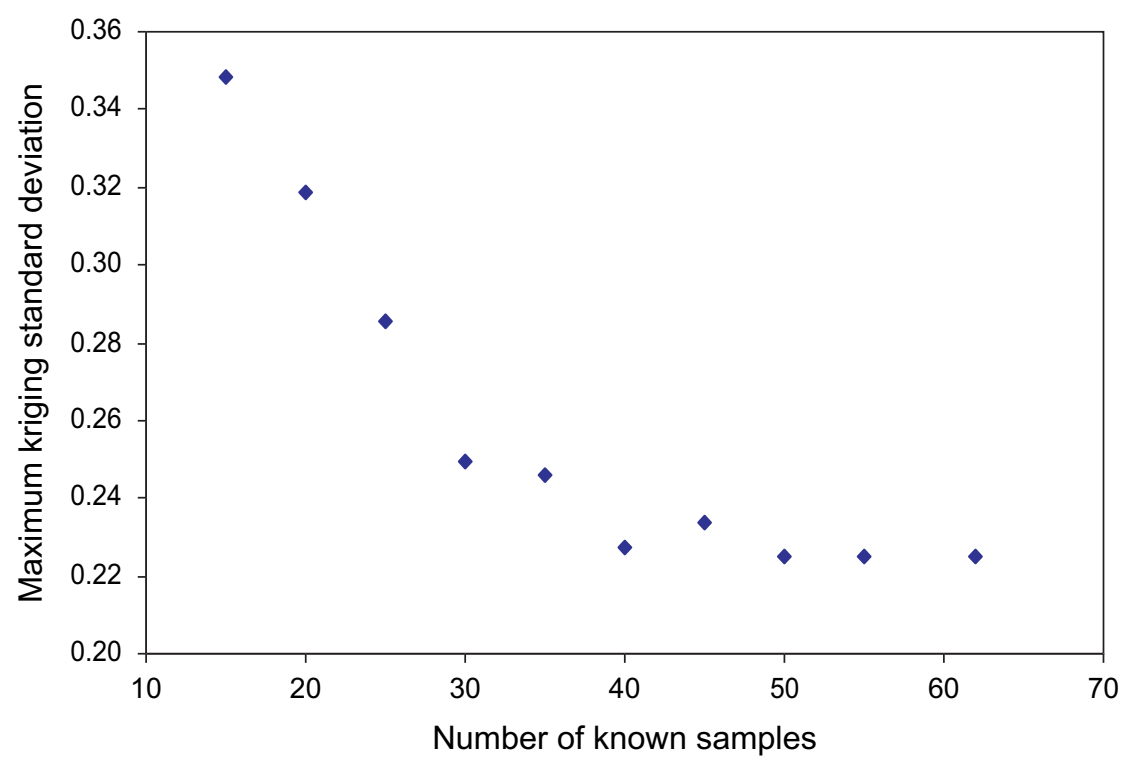

Fig. 9. Variation in maximum kriging standard deviation as a function of sampling frequency for seawater from Hillesøy.

exhibited by the actual data values. To achieve this, the modelled data set was subjected to semi-variographic analysis as for the actual data. For the Hillesøy data set the semi-variograms were established over the time period for which actual data was available this corresponds to the period between July 1997 and May 2002 as this is the extent to which the model data have been calculated. The calculated semivariograms and fitted models are displayed in Fig. 12. For both sets of data, the semi-variograms are comparable with respect to the range of correlation and the sill although nugget parameters exhibit some difference between modelled and actual data.

The nugget values of the semi-variograms produced for the model data are closer to zero than that for the actual data. As the nugget is representative of the unstructured or random component to the overall semi-variance (i.e. samples taken at exactly the same time will have slightly different values), it is likely that analytical error, sampling error and other uncertainties associated with the analytical procedure contribute largely to this value. The modelled data on the other hand does not include such uncertainties and are therefore more likely to produce a lower random contribution. The range, however, which is the parameter of most interest in the design of the sampling plan, for the semi-variogram of modelled data, is quite comparable to that produced by the actual series. The comparability of the semivariograms produced may indicate that in the case of designing a sampling scheme at a location where no previous data exists, it may be possible to employ models that describe the processes affecting the temporal structure of the data to make an a priori assessment of the semi-variogram. 


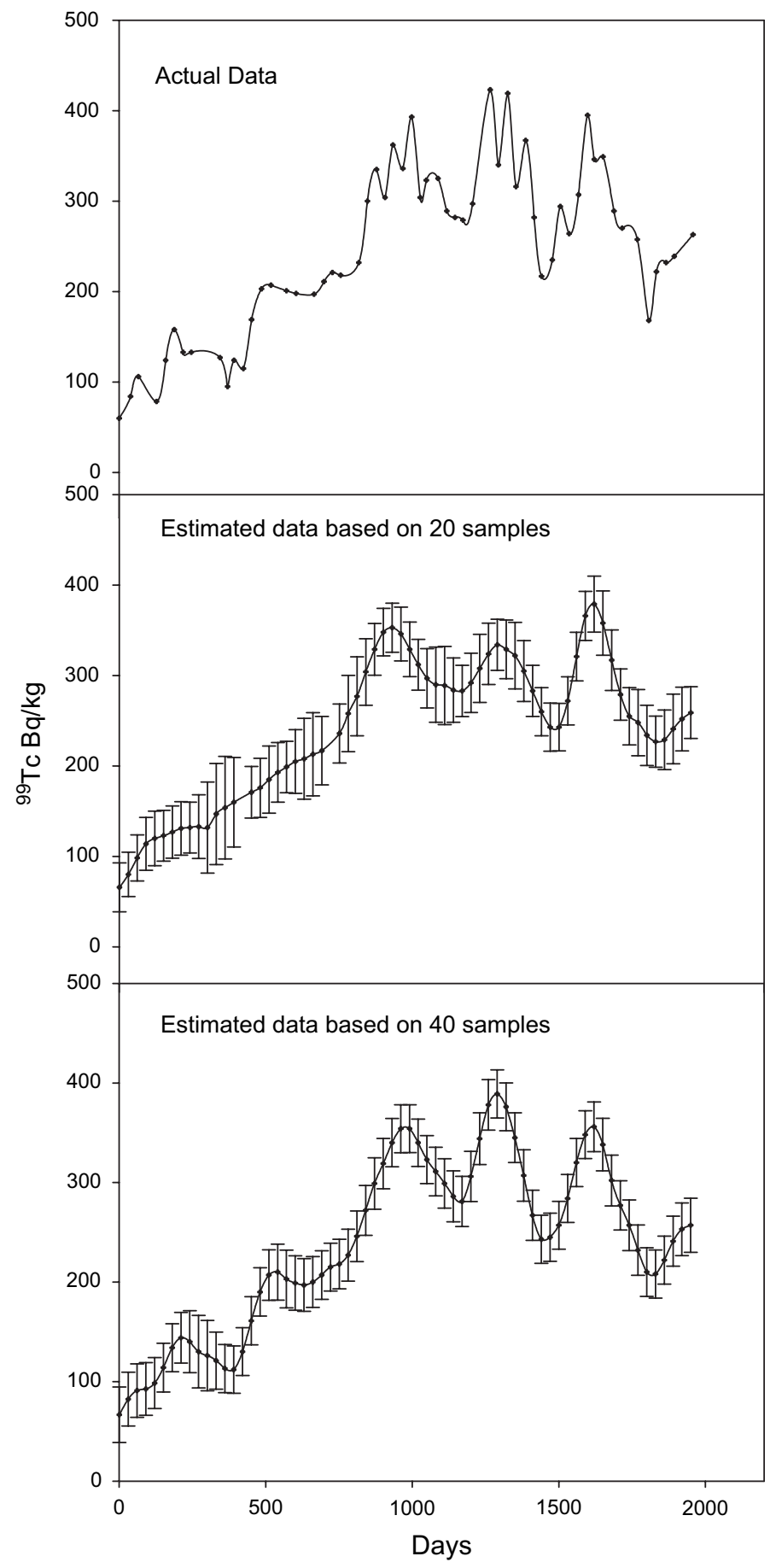

Fig. 10. Representations of ${ }^{99} \mathrm{Tc}$ activity over time for seaweed from Hillesøy based on the estimation procedure using 20 and 40 of the original data points compared with the actual data set. Error bars are the kriging standard deviations for the estimates. Note: uncertainty data for actual series are not provided. 


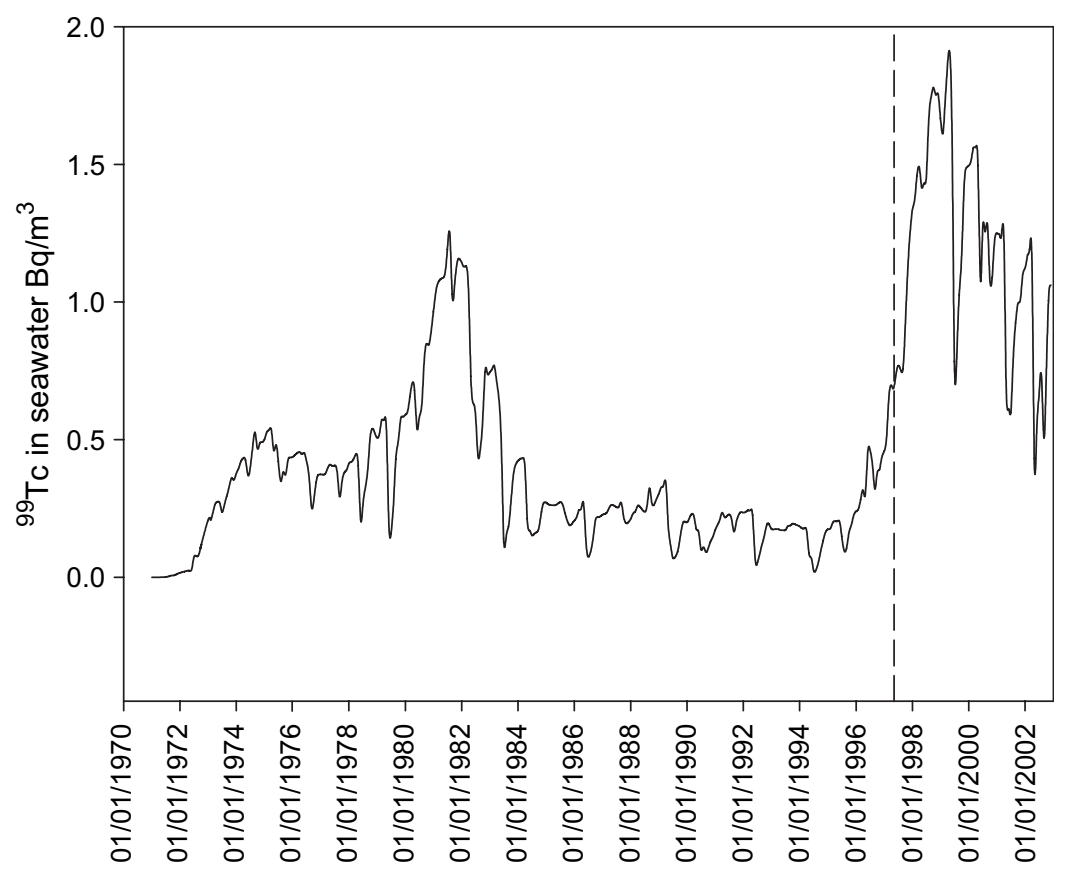

Fig. 11. NAOSIM model output for ${ }^{99}$ Tc levels in seawater at Hillesøy. Vertical dashed line denotes beginning of empirical measurements at Hillesøy, data from this point (July 1997) onwards being that employed in this study.

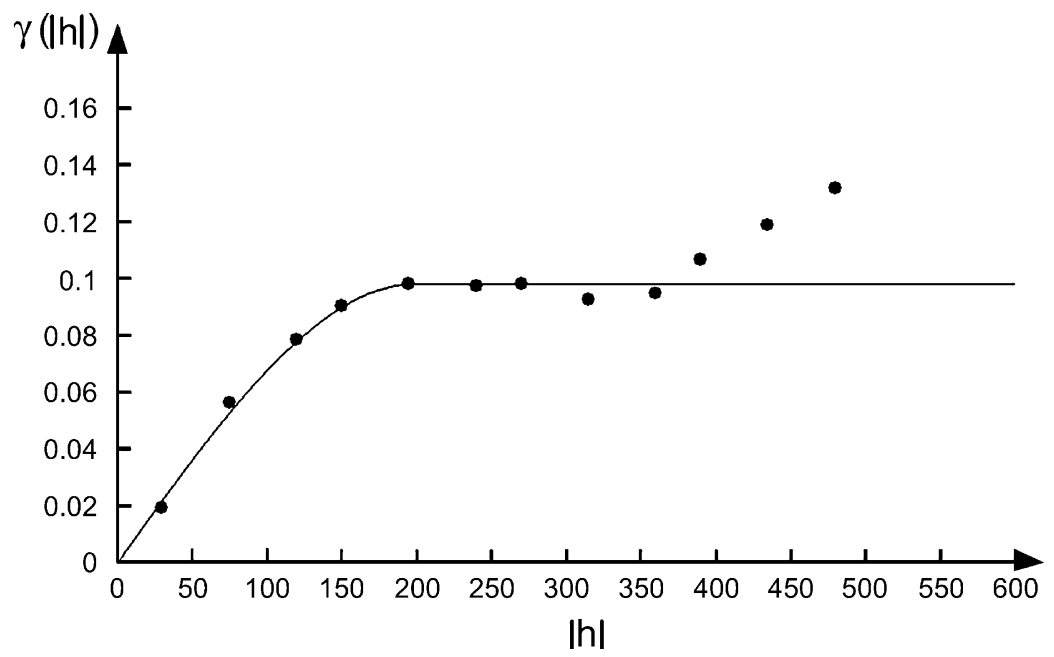

Fig. 12. Semi-variogram for modelled ${ }^{99} \mathrm{Tc}$ values in seawater (Hillesøy) over the time scale of the actual data. $\mathrm{Lag}(x)$ axis - days, $\gamma(h)$ axis $-\left(\mathrm{Bq} / \mathrm{m}^{3}\right)^{2}$. Model parameters - Spherical, range -210 days, sill 0.095 , nugget -0.0 . 


\section{Conclusions}

The application of semi-variography and kriging to the problem of optimising a sampling plan for the production of monthly ${ }^{99} \mathrm{Tc}$ values in seawater and seaweed has been assessed. Using an estimation error minimisation technique it was observed that with respect to producing estimated monthly ${ }^{99} \mathrm{Tc}$ values for seawater and seaweed, little improvement could be made in the quality of the estimates by sampling at higher frequencies than approximately every 50 days. For the time series studied, this would constitute a reduction in the number of samples required to record fluctuations in levels of this isotope. The use of an oceanographic model to provide an a priori assessment of the necessary parameters relating to the temporal structure was investigated for seawater data. The results indicate that it may be possible to deploy such models for these purposes in situations where previous data does not exist.

\section{Acknowledgements}

This work has been carried out as part of the RADNOR project (153568/720), funded by the Norwegian Research Council.

\section{References}

Aarkrog, A., Dahlgaard, H., Hallstadius, L., Holm, E., Mattsson, S., Rioseco, J., 1986. Time trend of ${ }^{99}$ Tc in seaweed from Greenland waters pp. 69-78. In: Desmet, G., Myttenaere, C. (Eds.), Technetium in the Environment. Elsevier, London and New York, p. 419.

Aarkrog, A., Boelskifte, S., Dahlgaard, H., Duniec, S., Hallstadius, L., Holm, E., Smith, J.N., 1987. Technetium-99 and Cesium-134 as long distance tracers in Arctic Waters. Estuarine, Coastal and Shelf Science 24, 637-647.

Beasley, T.M., Lorz, H.V., 1986. A review of the biological and geochemical behaviour of technetium in the marine environment. Journal of Environmental Radioactivity 3, 1-22.

BNFL, 1982-1991. BNFL Annual Reports on radioactive discharges and monitoring of the environment. British Nuclear Fuels Limited, Risley, UK.

Bondietti, E.A., Francis, C.W., 1979. Geological migration potential of technetium-99 and neptunium237. Science N.Y. 203, 1337-1340.

Brown, J., Kolstad, A.K., Lind, B., Rudjord, A.L., Strand, P. 1998. Technetium-99 contamination in the North Sea and Norwegian coastal areas 1996 and 1997. NRPA Report 1998:3, Østerås, Norwegian Radiation Protection Authority, p. 21.

Busby, R., McCartney, M., McDonald, P., 1997. Technetium-99 concentration factors in Cumbrian seafood. Radioprotection-Colloques 32, 311-316.

Cataldo, D.A., Garland, T.R., Wildung, R.E., Fellows, R.J., 1989. Comparative metabolic behaviour and inter-relationships of Tc and S in soybean plants. Health Physics 57, 281-288.

Chen, Q., Aarkrog, A., Nielsen, S.P., Dahlgaard, H., Hou, X., Yixuan, Y., Lind, B., Kolstad, A.K., 2001. Procedures for Determination of ${ }^{238,239,240} \mathrm{Pu},{ }^{241} \mathrm{Am},{ }^{237} \mathrm{~Np},{ }^{234,238} \mathrm{U},{ }^{228,230,232} \mathrm{Th},{ }^{210} \mathrm{~Pb},{ }^{210} \mathrm{Po},{ }^{99} \mathrm{Tc}$ and ${ }^{90} \mathrm{Sr}$ in Environmental Materials. Department of Radiation Research, NUK-202, Risø National Laboratory, Roskilde, Denmark, pp. 32.

Clarke, I., 1979. Practical Geostatistics. Applied Science Publishers, England, pp. 3-50.

Englund, E., Sparks, A., 1988. GEO-EAS: Geostatistical Environmental Assessment Software. Users Guide. USEPA Rep. 6004-88/033. USEPA, Las Vegas, Nevada. 
Flatman, G.T., Yfantis, A.A., 1984. Geostatistical strategy for soil sampling: the survey and the census. Environmental Monitoring and Assessment 4, 335-349.

Gäfvert, T., Føyn, L., Brungot, A.L., Kolstad, A.K., Lind, B., Gwynn, J., Sværen, I., Alvestad, P., Skipperud, L., Strålberg, E., Christensen, G.C., Salbu, B., Drefvelin, J., Dowdall, M., Rudjord, A.L., 2004. Radioactivity in the Marine Environment 2002. Results from the Norwegian National Monitoring Programme (RAME). StrålevernRapport 2004:10. Norwegian Radiation Protection Authority, Østerås, Norway, pp. 52.

Gerdes, R., Karcher, M., Kauker, F., Koeberle, C., 2001. Predicting the spreading of radioactive substances from the Kursk. EOS, Transactions, American Geophysical Union 82 (23), 253-257.

Herrmann, J., Kershaw, P.J., Dubois, P.B., Guegueniat, P., 1995. The distribution of artificial radionuclides in the English Channel, southern North Sea, Skagerrak and Kattegat, 1990-1993. Journal of Marine Systems 6, 427-456.

Karcher, M.J., Gerdes, R., Kauker, F., Koeberle, C., 2003. Arctic warming - evolution and spreading of the 1990's warm event in the Nordic Seas and the Arctic Ocean. Journal of Geophysical Research 108 (C2), 3034

Karcher, M.J., Gerland, S., Harms, I., Iosjpe, M., Heldal, H., Kershaw, P.J., Sickel, M., 2004. The dispersion of technetium-99 in the Nordic Seas and the Arctic Ocean: a comparison of model results and observations. Journal of Environmental Radioactivity 74 (1-3), 185-198.

Krige, D.G., 1951. A ststistical approach to seome basic mine valuation problems in the Witwatersrand. Journal of Chemical, Mettalurgical and Mining Society of South Africa 52, 119.

Leonard, K.S., McCubbin, D., Brown, J., Bonfield, R., Brookes, T., 1997. Distribution of technetium-99 in UK coastal waters. Marine Pollution Bulletin 37, 628-636.

Matheron, G., 1963. Principles of geostatistics. Economic Geology 58, 1246-1266.

Pannatier, Y., 1996. Variowin 2.2. Software for Spatial Data Analysis in 2D. Springer Verlag, New York. Srivastava, R.M., Isaaks, E.H., 1989. Applied Geostatistics. Oxford University Press, New York, pp. $319-350$. 